\title{
Ergonomically Design of Multipurpose Portable Wooden Table
}

\author{
D. R. Thawkar \\ Professor, B. C. Y. R. C. Umrer College of Engineering, Umrer
}

\begin{abstract}
In the field of manufacturing engineering product design plays a key role in turns of it geometrical like size, shape and its easiness for users. But in this paper we have to design a single universal table for fulfilling multiple purpose in a single product. Multipurpose wooden table is a table which can transform into tool, chair, comfort chair, tea table, centre table, Tea table, drawing table and dining table and this is achieve with the help of different mechanical linkages such as spring return, sliding joints, hinges, etc. To prepare our product the type of material should be properly selected considering design, safety and strength. 1. Wood: wood is readily available in market. it is economical. it is easily machine. Less in weight hence good for portability. 2. Brass: Has good mechanical properties. it is corrosion resistance. Self lubricating. 3. Mild steel: it has high tensile strength. Economical to use. Available in standard sizes. We made design with the help of pro E software which help us to make our visualization into reality And with the help of ANSYS software we calculated the different stress which would act on our when it would be made
\end{abstract}

Keywords: wheel chair, multipurpose portable desk, FEM

\section{Introduction}

In the field of manufacturing Engineering product design plays key role in turns of it geometrical parameters like size, shape and its easiness for users. For different purpose people has to buy different product like chair for sitting, dining table for keeping food, drawing table for drawing sheets, etc. But our project is design to use a single universal table for fulfilling multiple purpose in a single product.

This table would help the individual in many different way like first of all the main thing money, it is of low cost as compare to the coast of the entire thing which it will provide.So9 indeed it is a money saver. Other thing it is durable hence no requirement of replacement of the whole table. Muhammad zulfadlibin che zakari Nov.2008(1)

\section{Design of fabricate multipurpose portable desk}

The study of manufacturing was very important in order to carry out this project to ensure that the student understand on what are needed to do. This project is about designing and fabricate "Multipurpose Portable Desk" to help people easy to bring anywhere. This project involves the process of designing the table by using considering some of factor such as shape and ergonomic for people to use. After the design is complete, it was transformed to real product where the design is used as a guideline.

This project also required to ensure the safety for indeed of publishing. Methods and process involve in this project for instance joining using welding, rivet, shearing, bending and drilling. This project is mainly about generating a new concept of multipurpose and portable desk that would make easy to bring anywhere and more function. After all process had been done, this desk may help us to understand the fabrication and designing process that involved in this project

Mohan Kumar R. et al. 1 April 2012. (2)
Design of Multipurpose Wheel Chair for Physically Challenged and Elder People

Wheel Chair is a mobility device designed for shifting patients, moving physically challenged people from one place to another with the help of attendee or by means of self propelling. The wheel chair is divided into two different types based on the power used for mobility: 1. Manually powered wheelchairs. 2. Electric powered wheelchairs. Manual powered wheelchairs are driven by manual power which are again classified into foldable and non-foldable with or with out commode design. Electrical powered wheel chairs runs with electric power however manual operation is required to operate the joystick for the movement of the chair. The redesign of manual wheel chair was considered for this project. The design of wheel chair started by means of literature review to know its evaluation from earlier to the present generation. Market study was carried out to know the present competitors available in the market with cost analysis of the existing product. Ethnography study was done to observe the need, the importance of the existing product and to address the design gap in the existing product to the user need through questionnaries. The feedback was taken from different users and attendees, concept generation and design execution was done by the implementation of design methodologies like Quality Function Deployment, Mind mapping, Product Design Specification.

\section{S.M. Sapuan et al. 23 February 2007. (3)}

Design and fabrication of a multipurpose table using acomposite of epoxy and banana pseudo stem fibers. In this paper describes the fabrication of a multipurpose table using banana trunk fibre-woven fabric-reinforced composite material.

The aesthetic value coupled with strength and mechanical properties make banana trunk fibre-woven fabric-reinforced composites a suitable material for furniture making. Design and fabrication details using hand layup process are described. 


\section{International Journal of Science and Research (IJSR) \\ ISSN (Online): 2319-7064}

Index Copernicus Value (2015): 78.96 | Impact Factor (2015): 6.391

United states patent application publication Pub. No.: US 2006/0191446 A1 Pub. Date: Aug. 31, 2006. (4)

Multi-Purpose table for furnishing

A multi-purpose table for furnishing is anticipated, comprising: a top with a thickness and perimeter edges delimiting a Support Surface of the top' Supports on the underside of the top, a clearance aperture passing through the top and developing in such a way as to interrupt both the support surface and perimeter edges, a mobile element counter-profiled to the clearance aperture and aimed at reforming the support surface and perimeter edges, and fixing means between the top and mobile element to constrain the mobile element in a removable Way in the clearance aperture..

Carole Graham and Linda Dimmers. March 2001. (5)

\section{Furniture for Libraries}

Planning for furniture cannot occur too early in a project. The amount of furniture and equipment required to support a library's program will drive the amount of space and funding required to complete the project. Many planners begin to identify furniture and equipment needs during the programming phase. Planning for the furniture for a library project requires careful scheduling and budgeting and the assistance of a design professional with experience in the selection, evaluation, and procurement of specific items. When furniture is an afterthought it is frequently unavailable, mismatched to the architecture, or ill-suited for the intended location or purpose.

Lacey -jane walsh June 16, 2013 .

Multipurpose designed chairs

Song seung-yong offers consumers more than just or other fixtures when needed. One of these clever seats can actually hold unfolded laundry, with its overhead attachments, which makes it perfect for dorm room dwellers and messy students. These chairs are clearly more than just elegant furniture pieces. These would be perfect in minimalist living spaces.

After referring to the above described points, I initiated a step ahead in making a table that satisfies customers requirement with multiple functions in a single table.

\section{Objectives}

a) General Objective

1) To study the existing design of Table considering ergonomics concept : while surveying the market, we have designed a table that will consume less efforts of the human and will yield with the multiple functions in a single table. Aesthetically this project is been designed ,so that the individual using it will feel comfortable.

2) To study the enhancements in design and modifications in existing design: after the market survey we have accomplished a design of a table that can withstand with varieties in a single table.
3) Modeling and simulation of table design for stress Analysis : for the purpose of modeling we have used PRO-E software and for stress analysis we have used ANSYS-12

4) Fabrication of Table : with the help of above described surveying points, we concluded to design a table that will work as multifunctionality i.e chair, ironing table, tea table, easy chair, center table, drawing table and dining table, it took lot of efforts to tackle the obstruction while designing this particular table.

b) Specific Objectives

1) To plan the table structure.

2) To design different parameters related with the mechanical linkages and structure.

3) To made it available at lower cost.

4) To implement the manufacturing processes for creation of the sub-components

5) To assemble the subcomponent and check the reliability of the creation.

6) To test the product whether it is performing the intended task

\section{Finite-Element Modeling of A Multipurpose Portable Wooden Table}

Figure 1 shows the Stool structure FEA Modeling by ANSYS 12. . A 3-D element SOLED186 with three degrees of freedom and 20 nodes is used for modeling the plate structure. The table made of teak wood with the properties given in the table 1. With geometrical parameters of teak wood having Length $915 \mathrm{~mm}$, width $915 \mathrm{~mm}$, thickness $915 \mathrm{~mm}$. The table having length $458 \mathrm{~mm}$ width $458 \mathrm{~mm}$ and depth $458 \mathrm{~mm}$ shown in figure 1. Figure 2 shows the close view of applied table elements used in ANSYS to get FEA of stress and strain problem.

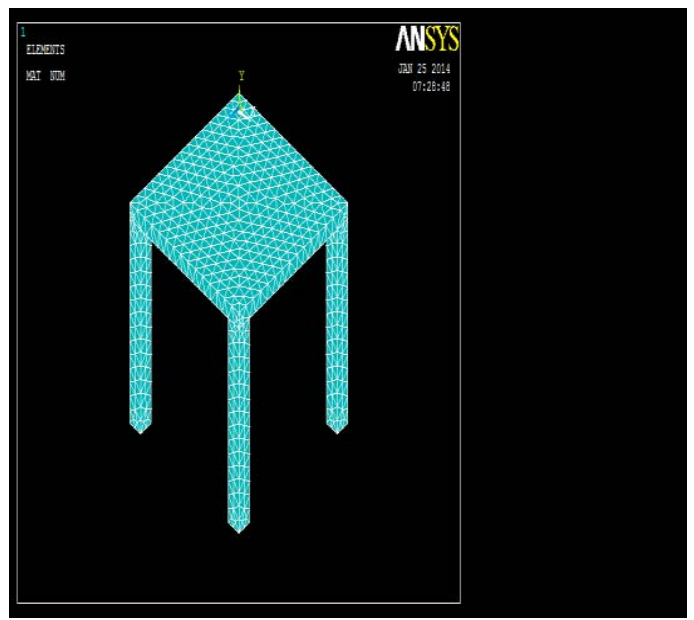

Figure 1: FEA model of TABLE built in ANSYS 12

Above figure shows the basic FEA model of a universal table with solid 180 as the material type. Other material properties are ellobrate in the table $\mathrm{x}$. 
International Journal of Science and Research (IJSR)

ISSN (Online): 2319-7064

Index Copernicus Value (2015): 78.96 | Impact Factor (2015): 6.391

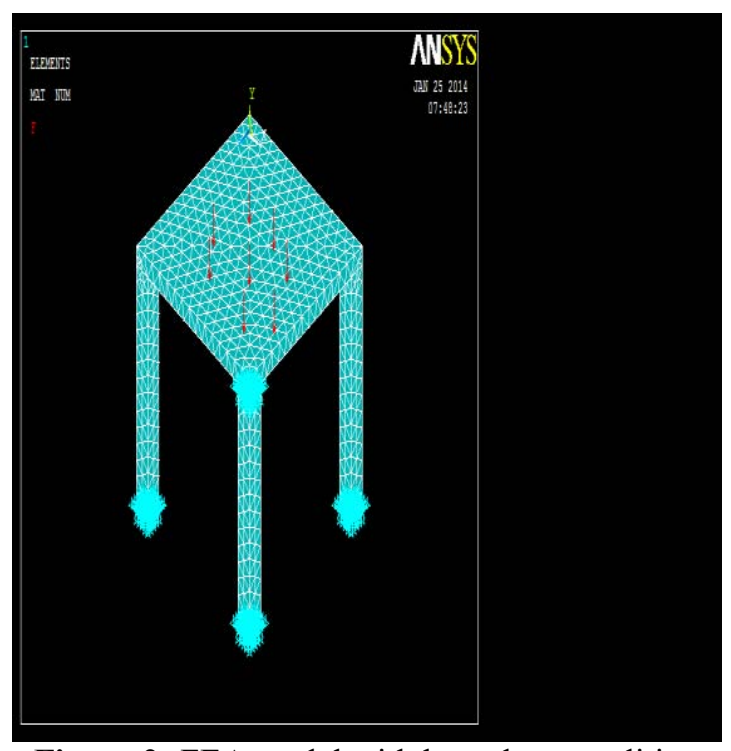

Figure 2: FEA model with boundary condition

Here boundary conditions are applied on the table i.e. zero degree of freedom at the end of legs of table.

Downward force is applied on table surface which is equal to $1000 \mathrm{~N}$, which could be sustain by the table design.

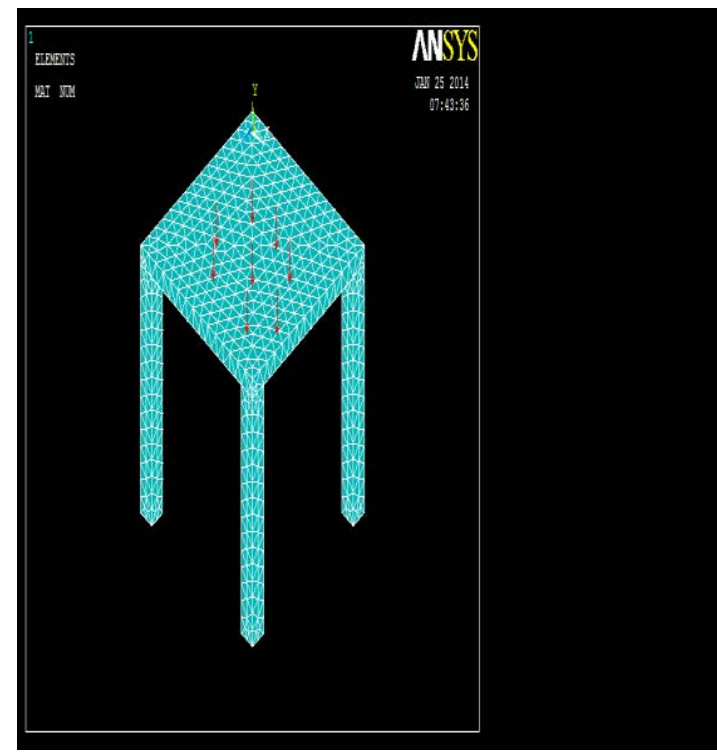

Figure 3: FEA model with force apply

Here we apply the $1000 \mathrm{~N}$ force downward to the table surface which could be sustain by the table.

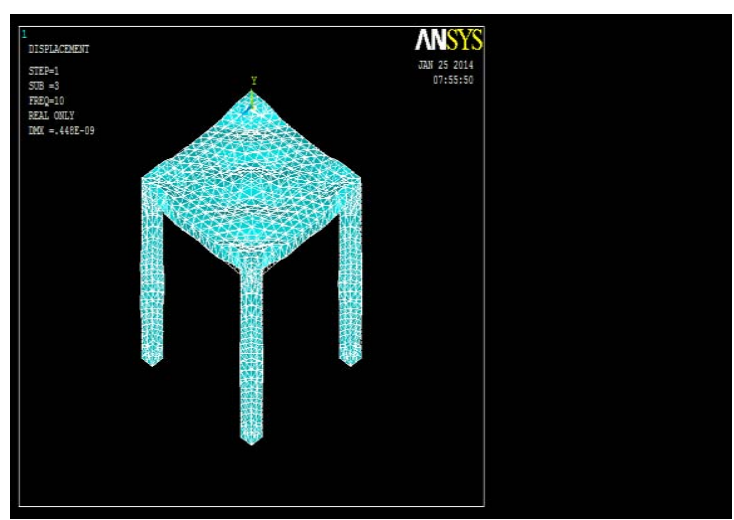

Figure 4: FEA model with maximum deflection

Here when we apply the $1000 \mathrm{~N}$ force downward to the table surface then figure shows the maximum deflection of the table surface

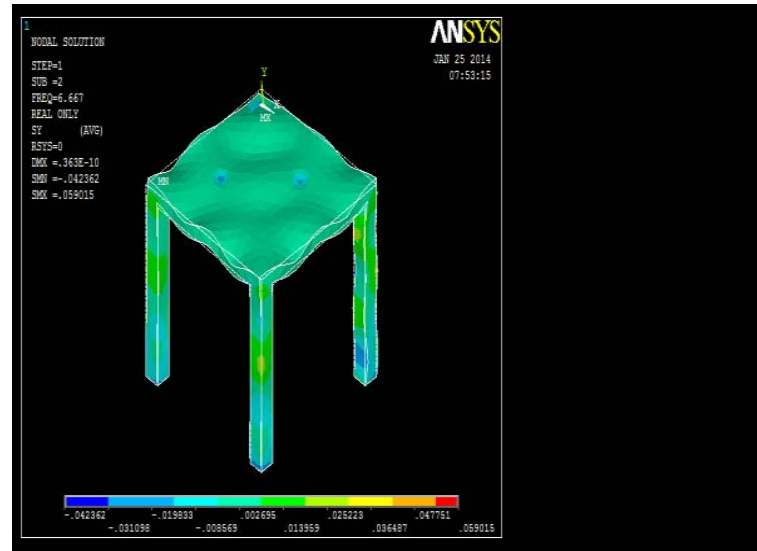

Figure 5: FEA model with y-direction displacement

Here due force apply on the table surface figure shows displacement in y-direction.

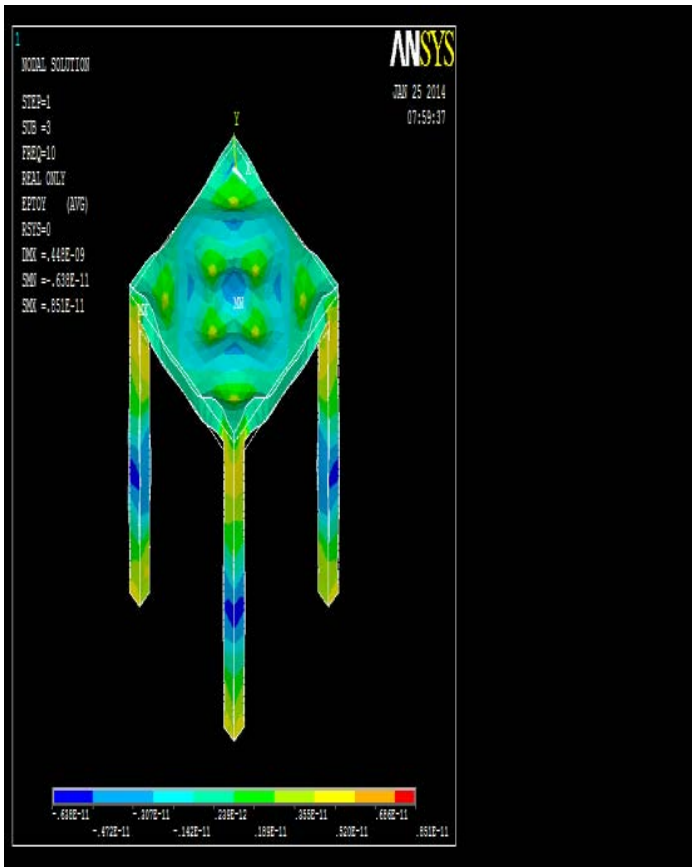

Figure 6: FEA model with y-strain

Here when the force apply on the table surface the table goes change in shape which means figure shows the $y$ strain. 


\section{International Journal of Science and Research (IJSR) \\ ISSN (Online): 2319-7064}

Index Copernicus Value (2015): 78.96 | Impact Factor (2015): 6.391

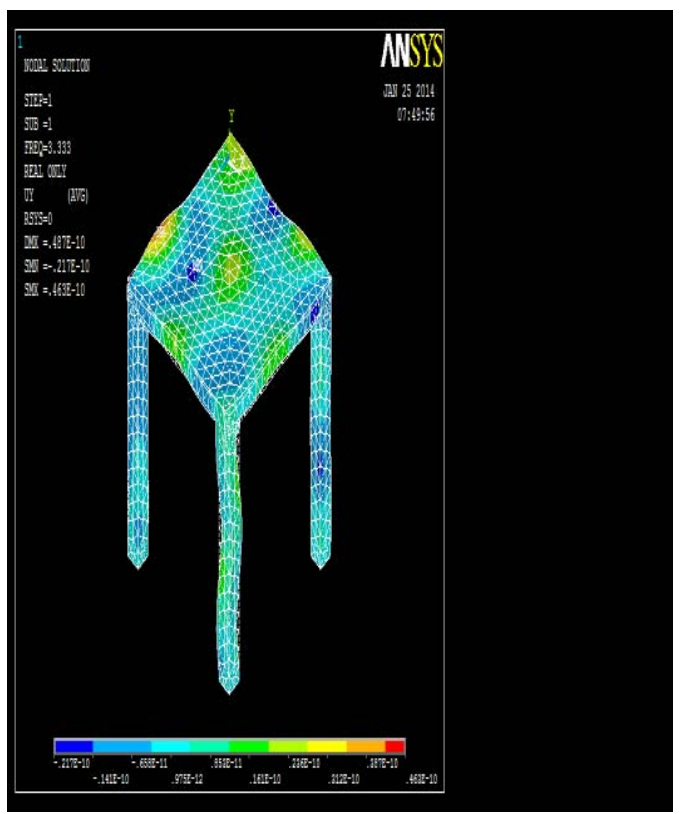

Figure 7: FEA model with y-stress

This figure shows the stress developed in the table when we apply the force of $1000 \mathrm{~N}$ on the downward of the table surface.

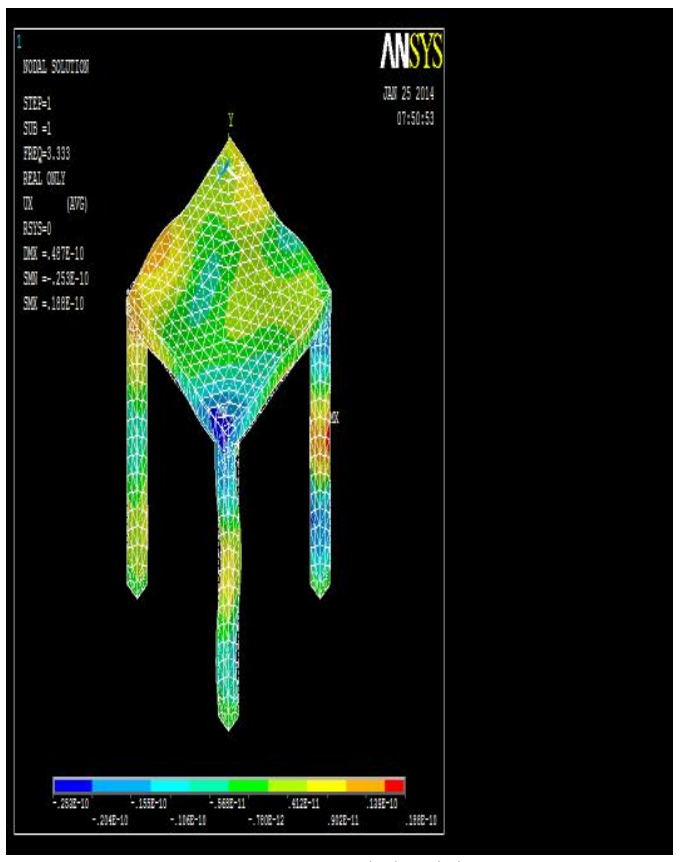

Figure 8: FEA model with $\mathrm{x}$-stress

Figure shows the $\mathrm{x}$ - direction stress when we apply the force on the table surface.

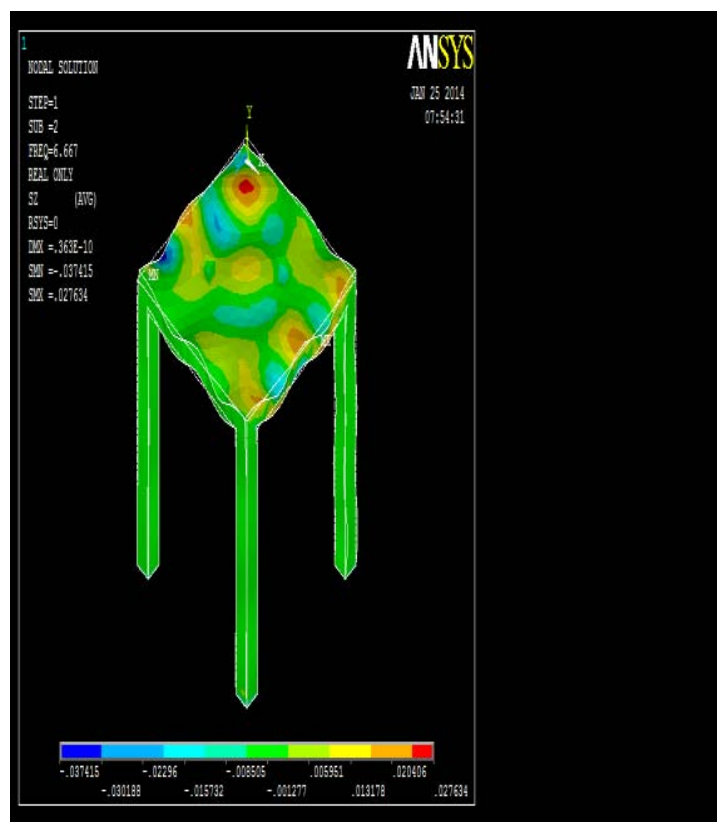

Figure 9: FEA model with z-direction displacement

Here z-direction displacement when we apply the force of $1000 \mathrm{~N}$ on the table surface.

Table 1: Input Geometric and Material Properties of TEAK WOOD Used to build FEA Model:

\begin{tabular}{|l|}
\hline - Substrate material: TEAK WOOD \\
\hline - Young's modulus $(\mathrm{GPA})$ \\
\hline - Poisson's ratio $(\mu \mathrm{s})$ \\
\hline - Density $\rho(\mathrm{kg} / \mathrm{m} 3)$ \\
\hline - Length $\times$ width $(\mathrm{mm})$ \\
\hline - Thickness $(\mathrm{mm})$ \\
\hline
\end{tabular}

Table 1 contains the material properties' data or the teak wood.

The processing of the geometry and finite-element mesh generation is provided by ANSYS processing analysis

\section{Manufacturing}

Multipurpose portable table is manufactured by using various joints of wood working and mechanical linkages.joinery is a part of wood working that involves joining together pieces of woods to create furniture, structures and other items the characteristics of wooden joints strength, flexibility, toughness, appearance etc are derived from the properties of joining materials and from how they are used in the joints

Four mechanisms are used in the manufacturing process

1) Sliding mechanism

2) Locking with spring return mechanism

3) Spring return mechanism

4) Arm mechanism

All the mechanisms are manufactured by using brass material which is corrosion free and rust free and also it is easy machine able. 


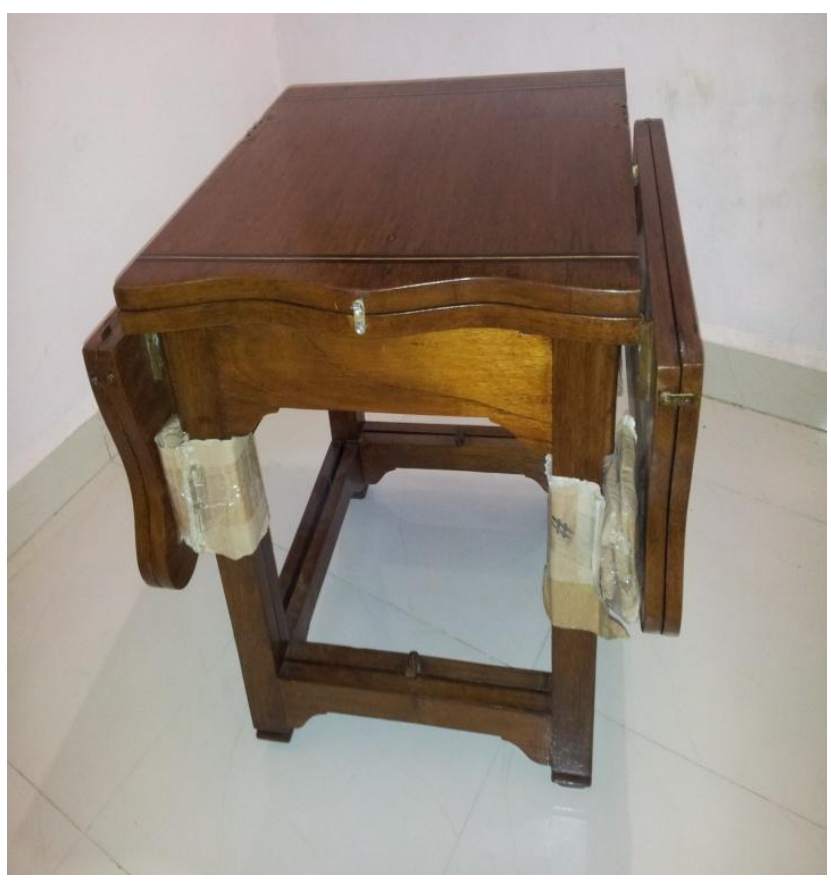

The table shown in the above image is manufactured by using the above described mechanisms which is made by using brass and teak wood with the help of cutting machine, hacksaw, planner etc. And hence the table can transform into various forms.

Mortise and tenon joint is used in the table which is simple and strong .mortise and tenon joint is used has been used many years ago by the wood cutters to join pieces of wood mainly when the adjoining pieces are at a angle of 90 degree.

The tenon is formed to the end of a member generally referred to as a rail and is inserted into a square or rectangular hole cut into the corresponding member. The joint may be glued, pinned, or wedged to lock it in place.

Raw wood is not in a condition so that it can be used as a tool, so planner is used to fabricate it, after fabrication a shape is given with the help of hacksaw and file. Aesthetic look is done with the help of spray machine and polish. finally polishing is done and the design and fabrication of table is accomplished.

\section{Application}

1) At its initial position is a tool which can use for keeping pot for show purpose, for keeping telephone, for keeping books, etc.

2) From initial position if we pull the slide flaps of table then the table as centre table. At this position we can use for writing purpose.

3) To used the table as chair from initial position we have to just open the upper top surface in the and the lock the upper top surface in the locker by the locking arm. Now it will serve as a chair. for comfort we can adjust the chair angle at 30 and 60 .

4) It also for using the table as drawing table from the initial position of table.

5) For using this table as dining table. From the position of drawing table we have to slide the top surface then unlock the lockers. After that first we have open the top surface and then open the both the flaps.

\section{Conclusion}

Here we proposes a FEA design of a universal table and try to check its sustainability in all respect like, max deflection, maximum strain induced and max stress induced in the table material i.e. wood.

As it would be concluded by FEA modeling that our design is well ok from all aspects of design. So our project would be welcome not only in houses but also in libraries, offices, school ,colleges, etc. since it will provide them dining table at lunch and at other time it can be used as a centre table, drawing table or chair

Using pro E and Ansys we done the modeling and different analysis of our project

\section{References}

[1] Muhammad Zulfadlibin Che Zakaria, Nov2008, Design Of Fabricate Multipurpose Portabl Desk, Core Design magazine \& Resource.

[2] Mohan Kumar R.1, Lohit H. S.2, Manas Ranjan Mishra 3, Md. Basheer Ahamed4, 1 April Design Of Multipurpose Wheel Chair For Physically Challenged And Elder People, Ethnographic Research.

[3] S.M. Sapuan1*, N. Harun1, and K.A. Abbas2,23 February 2007, Design And Fabrication Of A Multipurpose Table Using A Composite Of Eposy And Banana Pseudostem Fibres, Journal Of Tropical Agriculture 45 (1-2): 66-68.

[4] Diego Discacciati, Aug. 31 2006,Multipurpose Table For Furnishing, United States Patent Pub. No. US 2006/0191446 A1.

[5] Carole Graham and Linda Demmers, mar, 2001, Furniture For Libraries, Libris Design Magazine.

[6] Lacey-jane walsh, Jun16 2013, Multipurpose Designed Chairs, Library Of Congress Cataloging.

\section{Author Profile}

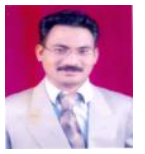

Prof. D.R.Thawkar is M.Tech (Industrial Engg), B.C.Y.R.C.Umrer college of Engineering, Umrer 